\title{
The impact of technology on external architectural appearance
}

\author{
Aako Noory M.Shari* and Amjad Muhammed Ali \\ Department of Architecture, College of Engineering, University of Sulaimani, Sulaymaniyah, Iraq \\ *Corresponding Author: ako.mohamad@univsul.edu.iq
}

Submitted: 03/05/2020

Revised: $\quad 16 / 11 / 2020$

Accepted: $23 / 11 / 2020$

\begin{abstract}
Losing the ability to remember certain images of a specific building in the human's mind is one of the problems these days, as this may make him feel the loss of its coordinates and lack of familiarity with his surroundings, and this happens when the architectural facades change and appear in more than one image. This paper focuses on new concepts of building façades, far from image constancy, which has been a great part of its conceptual structure. The study aims to discover the changes introduced by technology to the concepts of building façades, as it is important to deal with them in their new scope and adapt them to other parts of the components of the architectural forms of buildings. To achieve that, the study discusses the conceptual structures of building façades designed by new and old architecture pioneers. The paper is based on a comparative study to examine whether the facades of buildings for new architects have lost parts of their concepts and appear in a new and different way, compared to the basic components of the concept of architectural facades, depending on the characteristics of image constancy.
\end{abstract}

Keywords: Architectural Appearance; Change; Façade; Image Constancy; Technology.

\section{INTRODUCTION}

The architectural appearance refers to the visual image of the building from which the viewer can observe the internal and external surfaces and details of the building. This research is focusing just on the external appearance or the architectural façade, which is the front elevation of a building (Milnes, 1994); it will try to find out the impact of technology on a specific element of architectural form, which is the architectural façade, exactly on its concept, depending on the characteristic of image constancy. The terms of kinetic, dynamic, and media facades are the challenges for the ordinary concept of the façade and its constant images. Obviously, it can be seen that the impact of technology on architecture, as a product or as a kind of techniques, brings challenges to architectural appearance. Architecture has to provide a shelter that protects its inhabitants. On the other hand, it must create an exterior physically adapted to its functions and visually impressive, inviting or deterring, and informative (Arnheim, 1977).

Architectural appearance was constant and has resisted kinetics except in small details till the early attempts to change (Jules Moloney, 2009), while modernism banned images; it stated that architecture is prohibited from putting anything but itself (Ilka \& Andreas Ruby, 2007). To keep pace with technological progress and meet the desire for change, there have been attempts to resist the image constancy in architecture, as it can now be seen as a prelude to architectural schools nowadays between kinetic, digital, and smart, depending on the very bases of architectural elements in translation and rotation (Schumacher et al., 2010).

Dynamic or changeable facade offers occupants possibilities to choose the life style they want. Consequently, it does not only identify occupied places, but it also provides authentic features of indoor life (Peng Liu, 2001), and 
thus, the façade becomes more powerful than ever (Dan Hill, 2008). Besides, architecture gives its message in an advanced way of communication as the building can become a medium of the communication itself (Schieck, 2006), while simplicity and smart behavioral system applications are the key of kinetic façades design (Sharaidin, 2012). Media façade allows designing charming buildings by moving the physical shapes or manipulating the lighting, as the color of the buildings may change throughout the day continuously (Bawa, 2019). Designing buildings with colorful and dynamic facade is a growing trend currently by incorporating digital media tools (Aydogan, 2009). This explains that one of the architect's attempts to make buildings in harmony with nature is by engaging smart design (Kroner, 1977).

\section{PROBLEM}

This study is considering the architectural facade that has a certain concept, as previous studies talked about in this field. One of the main properties of architectural façades concept is image constancy. It means that there is just one image of each certain façade of any building, so there is just one mere appearance for each one. Traditionally, the design of a building's façade is "static", where the external environmental boundary conditions are designed to be constantly changing. As a result, traditional facades are not capable of adapting and responding to various changes that they are exposed to (Nady, 2016).

Facade plays a great role in forming and presenting the architectural form and gives a certain message, while the impact of technology gives façade the opportunity to change; it loses some of its concept. This change leads to a change in the architectural facade concept despite emergence of new undefined ones with different properties.

\section{RESEARCH METHOD}

The research depends on a comparative study between 10 samples of building facade designed by old pioneers (O.) (figures 1-10) with the same number of facade examples designed by new pioneers (N.) (figures 11-20) in order to obtain the ratio of change in façade image of each one and consider the high ratio as an indicator of losing a part of façade concept, which is image constancy. Table 1 represents measuring the ratio of changes in façade image (Change), while the image change in each type is having a value from $0-2$, where 0 means no change or it has image constancy, and 2 means high grade of change. The research will find (Change) for each sample by collecting (horizontally) the values of change in five sub categories of physical body, lighting, color, solid and void, and prominence and concavity, where each indicator has 3 grades in weight, which means that it is possible to get the grade of each certain sample in a total of 15 grades, and by collecting summation of (Change) vertically, it is possible to get the summation of all old pioneers' projects or new pioneers' projects samples. This easily leads to finding the ratio of change in façade image for all the samples in the same column by collecting them vertically and calculating the ratio.

On the other hand, it is easy to get the ratio of change in façade image, in any subcategory, for all O. or N. samples by collecting values vertically for each column and calculating the ratio.

\section{CASE STUDY}

The research represents 10 examples (fig. 1-fig. 10) of old pioneers buildings, having facades with ordinary concepts; at the same time, it represents 10 other examples (fig. 11-fig. 20) of new pioneers buildings, having facades with new concepts, and it is trying to compare them in order to get the grade of change in image in each one of them.

However, the comparison is not between any two buildings; yet, the research tried to select the same type of buildings in the same sequence for each group (1-11 or 2-12 for example). 


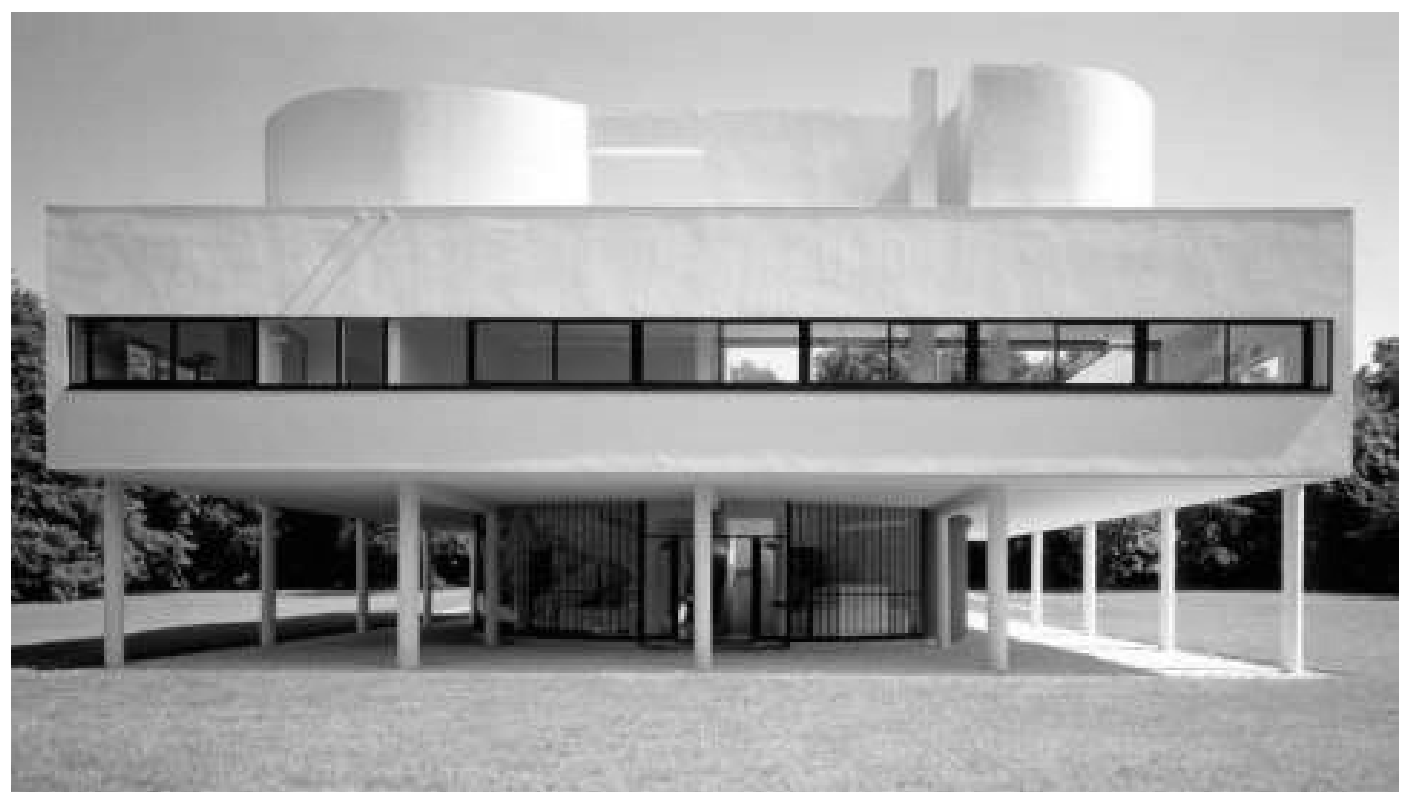

Figure 1. Villa Savoye by le Corbusier, Paris, France

(https://www.architecturaldigest.in/content/iconic-house-villa-savoye-le-corbusier/).

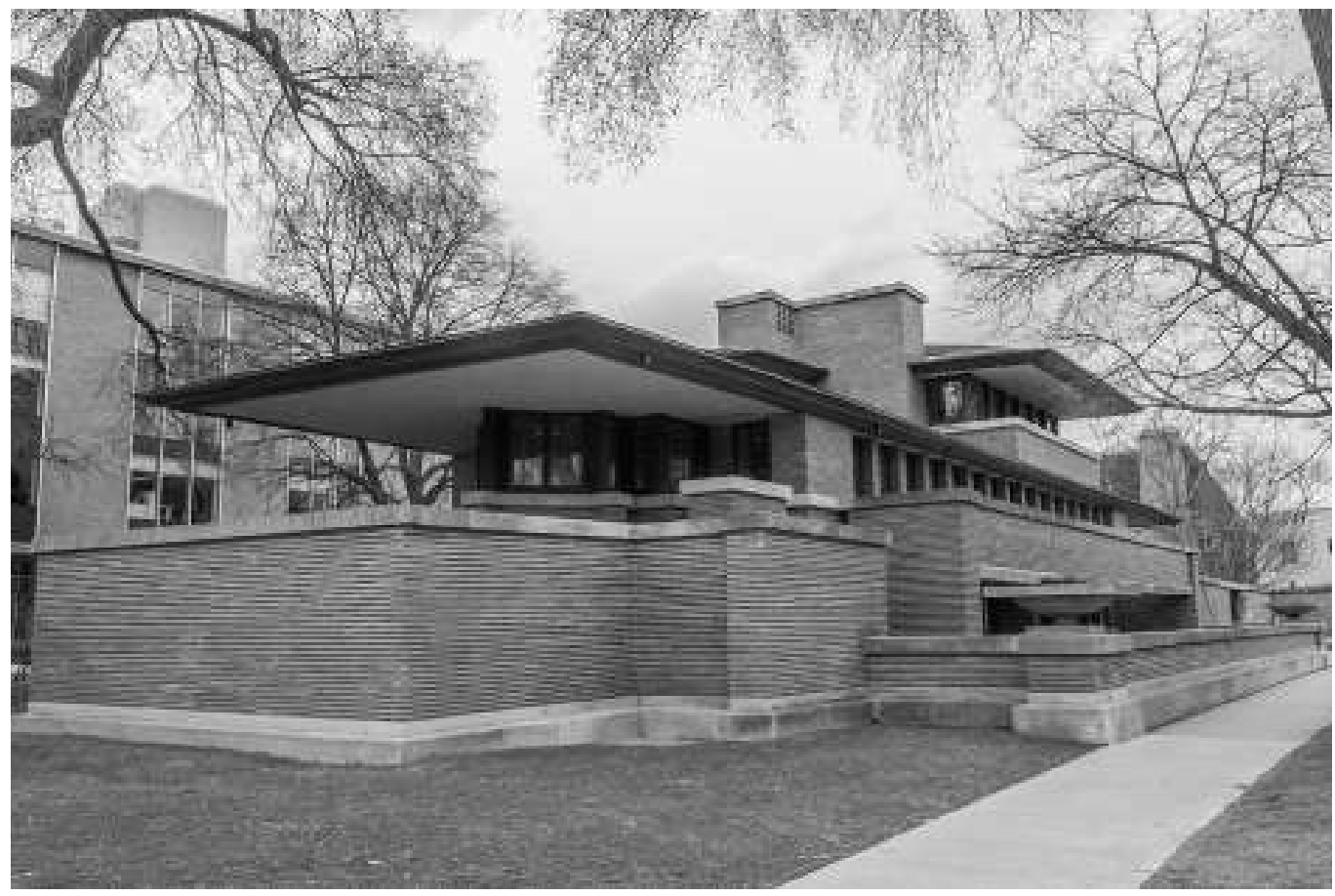

Figure 2. Robie House by Frank Lloyd Wright, Chicago, USA

(https://www.chicagomag.com/real-estate/April-2018/Inside-the-Renovation-of-Frank-Lloyd-Wrights-Robie-House/\#/0). 


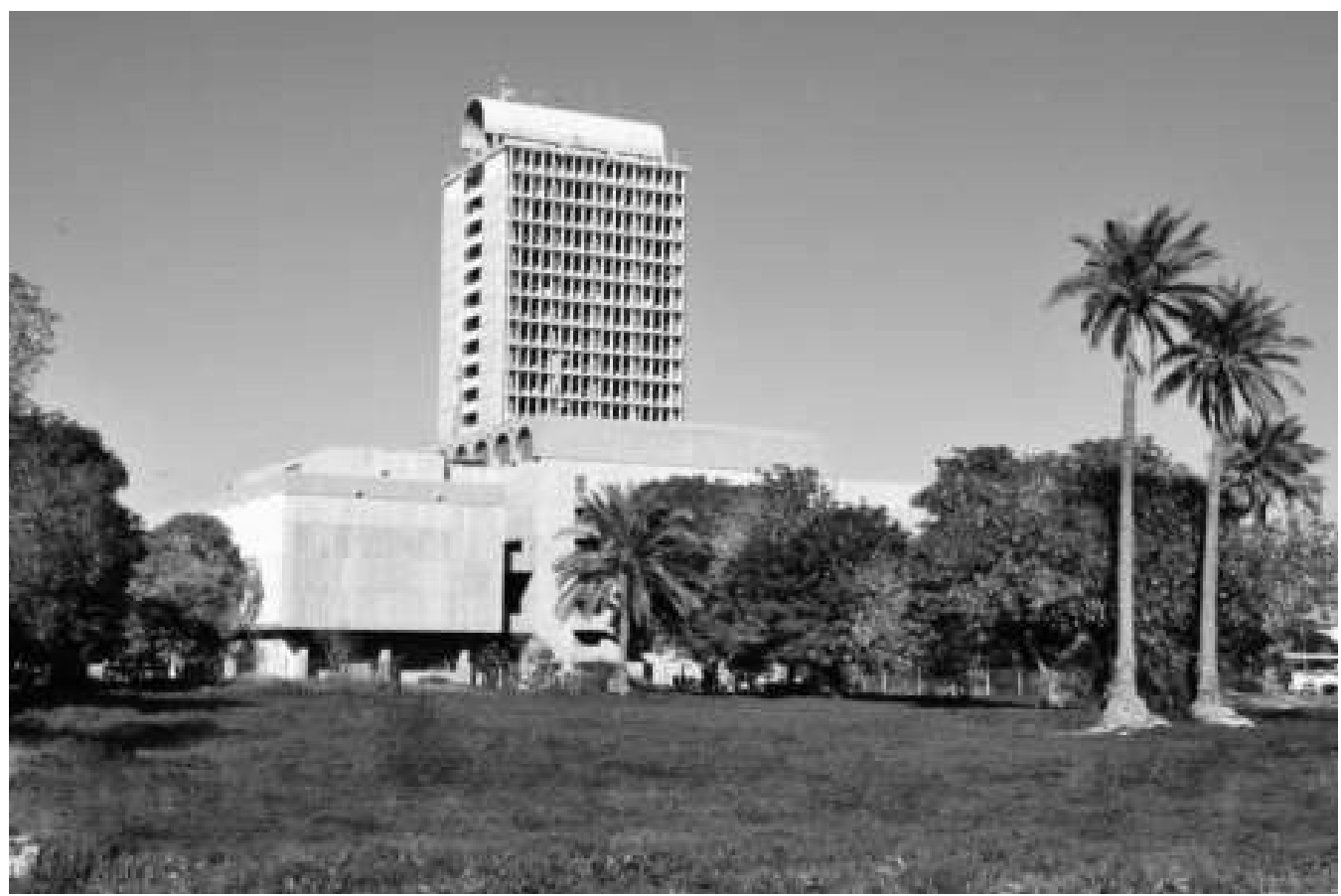

Figure 3. Baghdad University by Walter Gropius, McMillan, Baghdad, Iraq (https://site.unibo.it/waladu/en/uni-baghdadvteam).

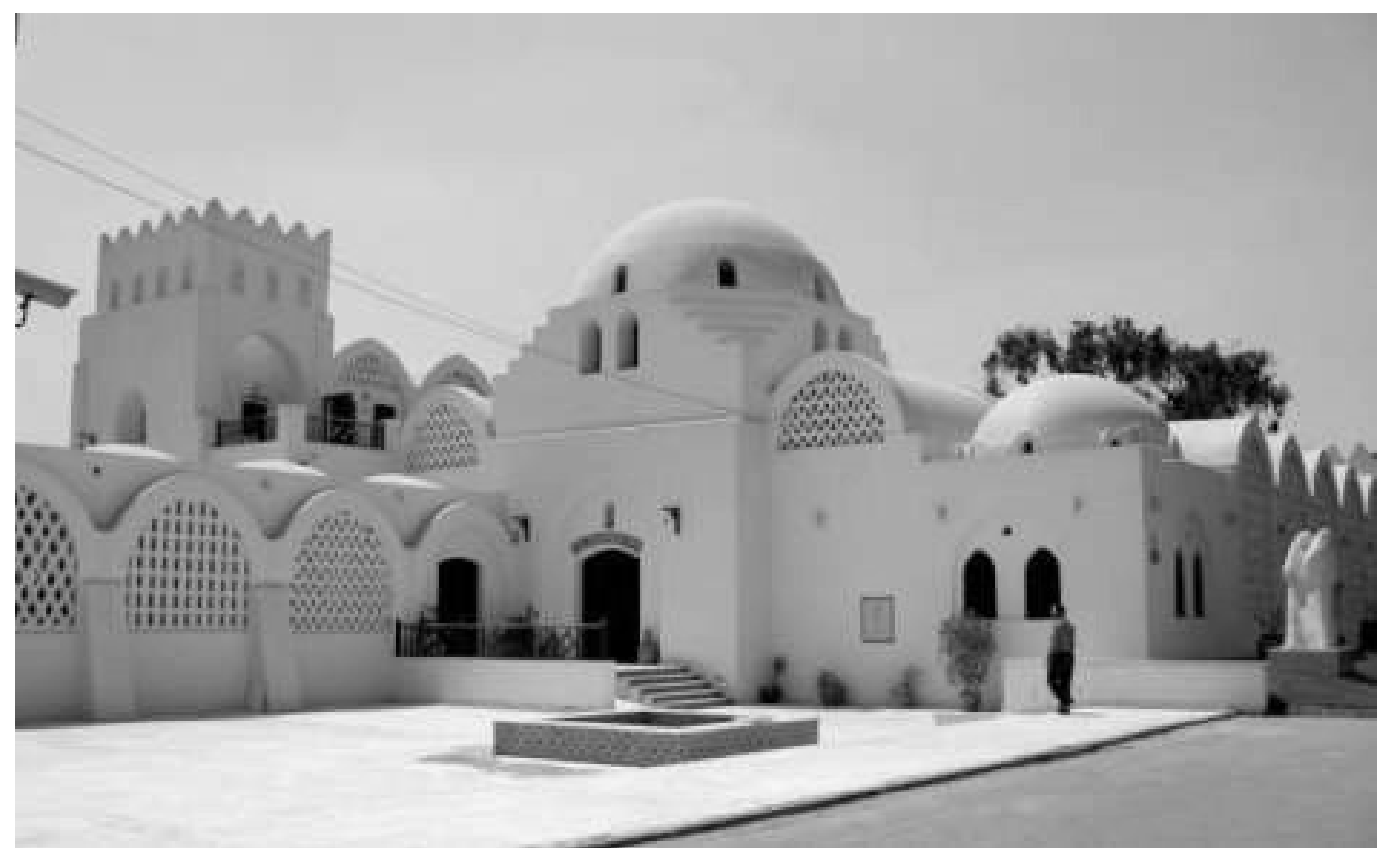

Figure 4. Village of new Gourna by Hasan Fathy, Egypt (https://cairoscene.com/ArtsAndCulture/35-Spectacular-Structures-by-Egypt-s-Architectural-Legend-Hassan-Fathy). 


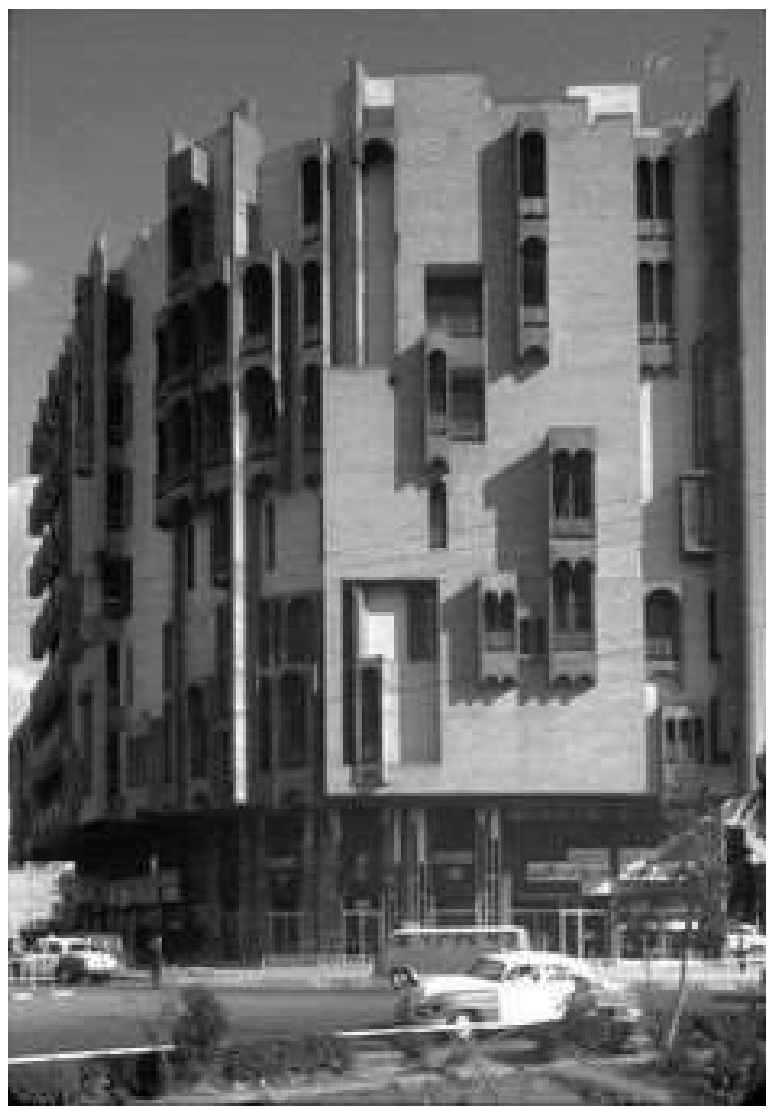

Figure 5. Iraqi federations of industries by Rifat Chadirji, Baghdad, Iraq (https://i.pinimg.com/236x/cd/f3/50/cdf35093ed224b8fad6ea3a6ad36c971.jpg).

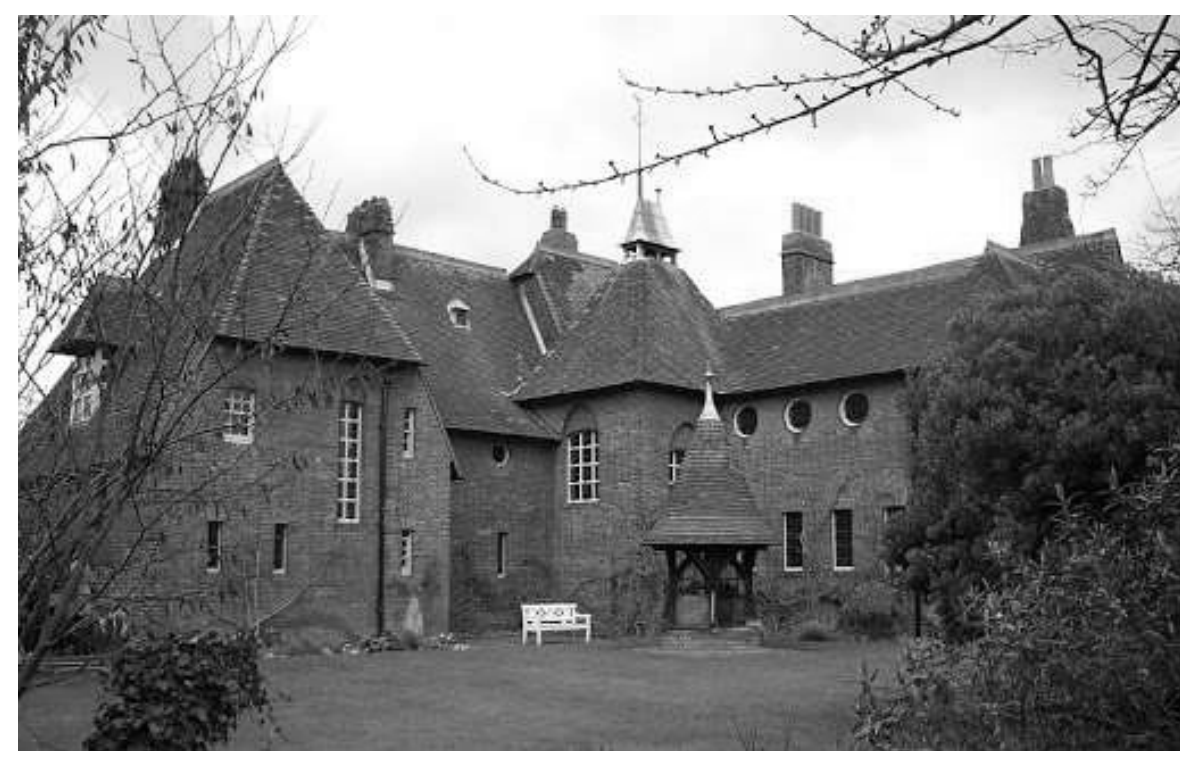

Figure 6. Red House by William Morris and Philip Webb, Bexleyheath, England (https://smarthistory.org/william-morris-and-philip-webb-red-house/). 


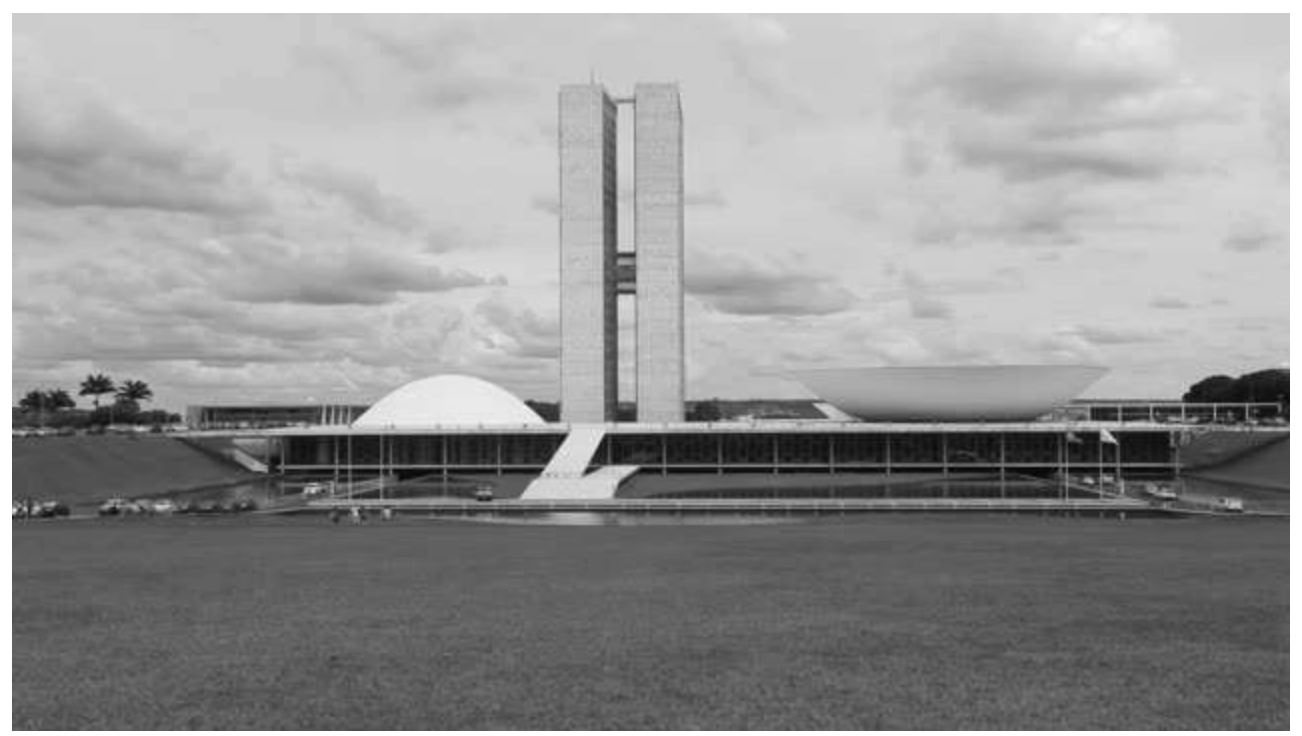

Figure 7. Brazilian parliaments building by Oscar Niemeyer, Brazil

(https://www.gettyimages.com/videos/brazilian-nationalcongress ?sort $=$ mostpopular $\&$ phrase $=$ brazilian $\% 20$ national $\% 20$ congres $)$.

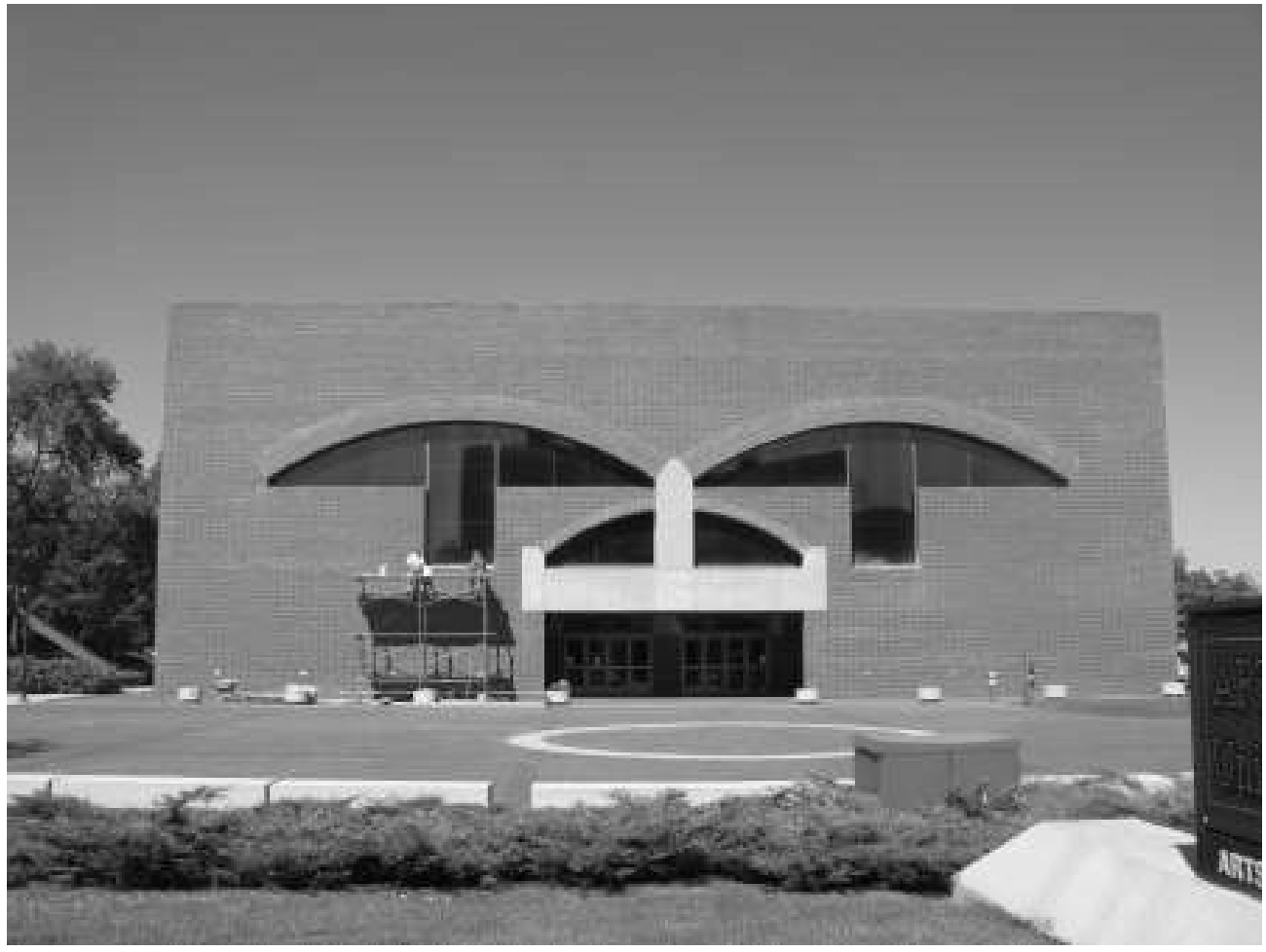

Figure 8. Arts United Center by Louis Khan, Indiana, USA (https://en.wikipedia.org/wiki/Arts_United_Center). 


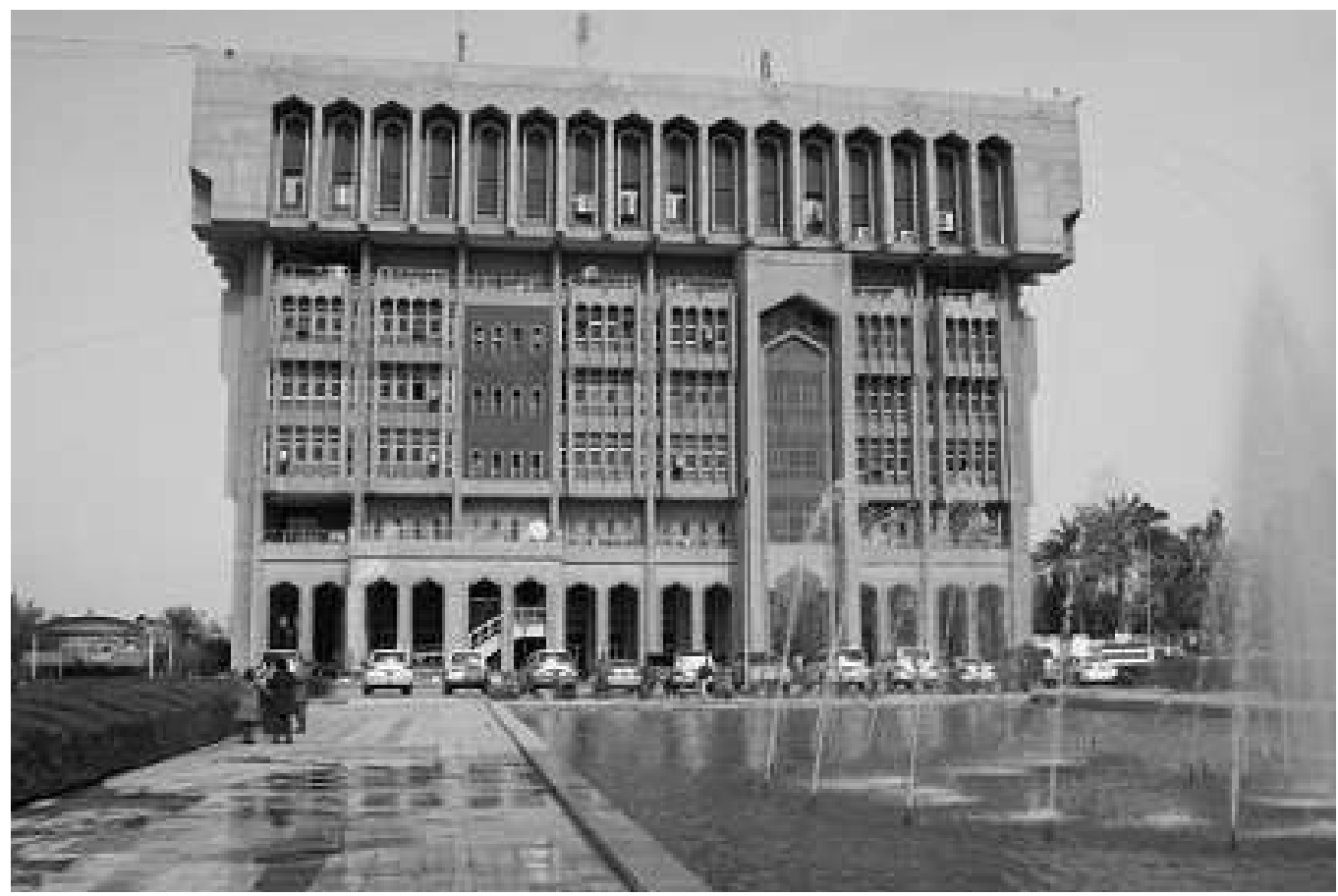

Figure 9. Baghdad Municipality by Hisham Munir, Baghdad, Iraq (http://almasalah.com/MediaStorage/GalleryImages/11351.jpg).

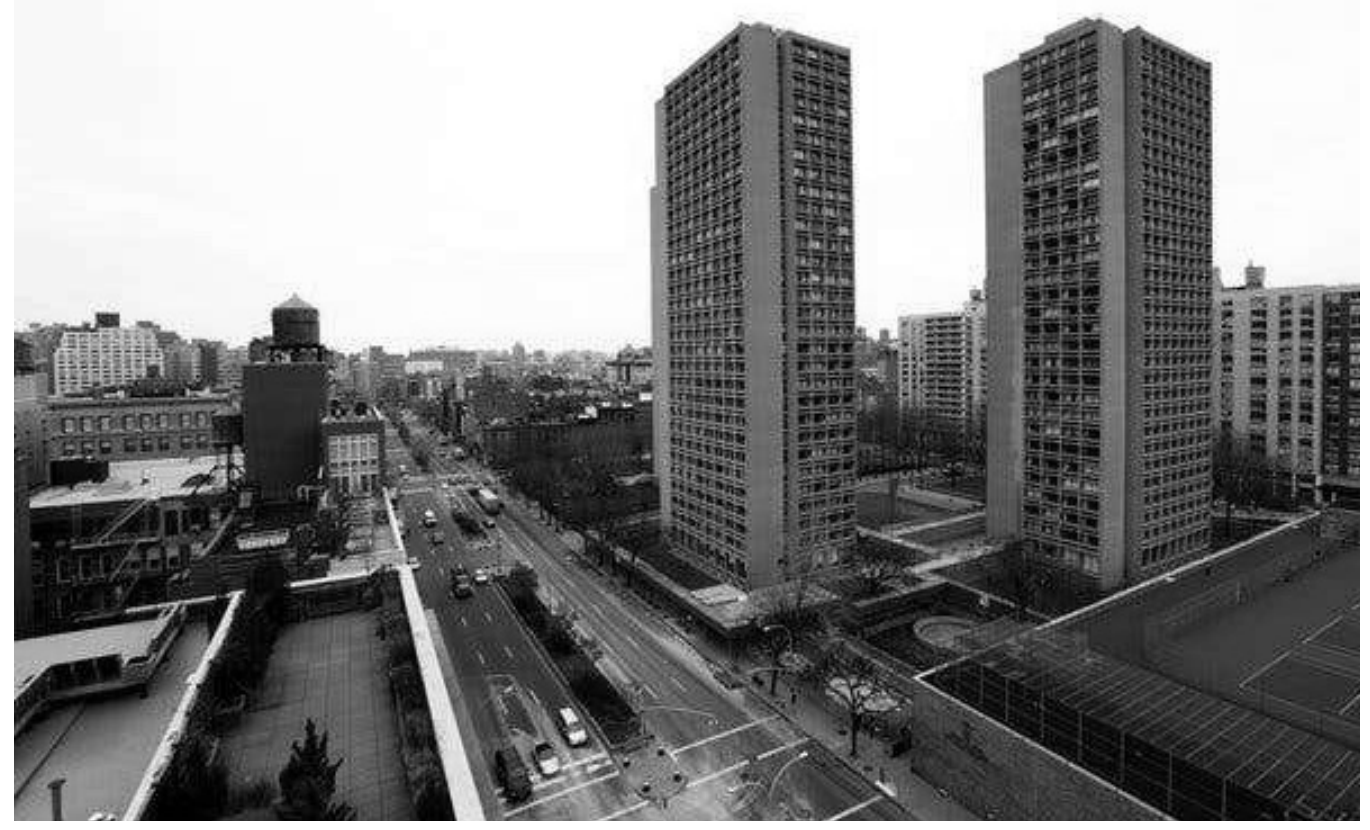

Figure 10. The Silver Towers at New York University by I M Pei, New York, USA (https://static01.nyt.com/images/2016/01/30/obituaries/16Pei-obit12/IMPei-obituary-slide-CIG7articleLarge.jpg?quality $=75 \&$ auto $=$ webp\&disable $=$ upscale). 

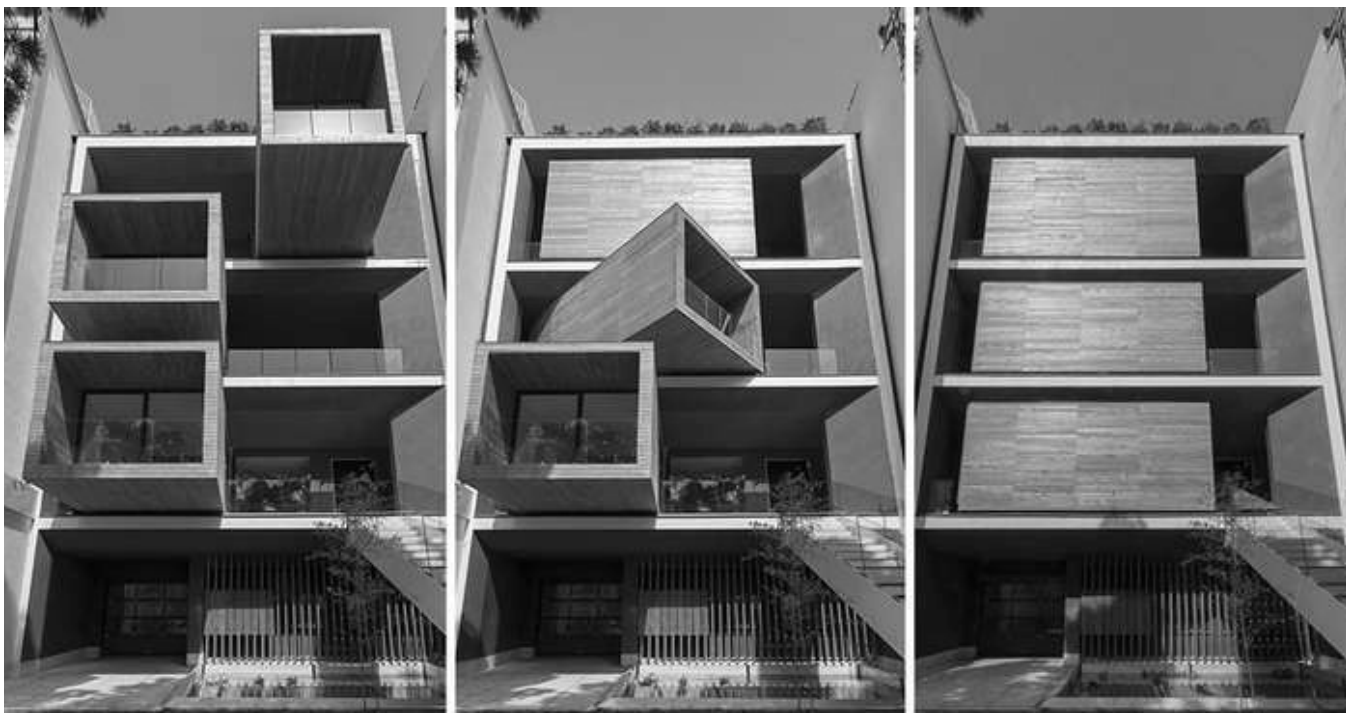

Figure 11. Sharifi-ha House by Alireza Taghaboni within Next Office Architects, Tehran, Iran (https://static.boredpanda.com/blog/wp-content/uploads/2015/06/rotating-romms-house-tehran-fb_700.jpg).

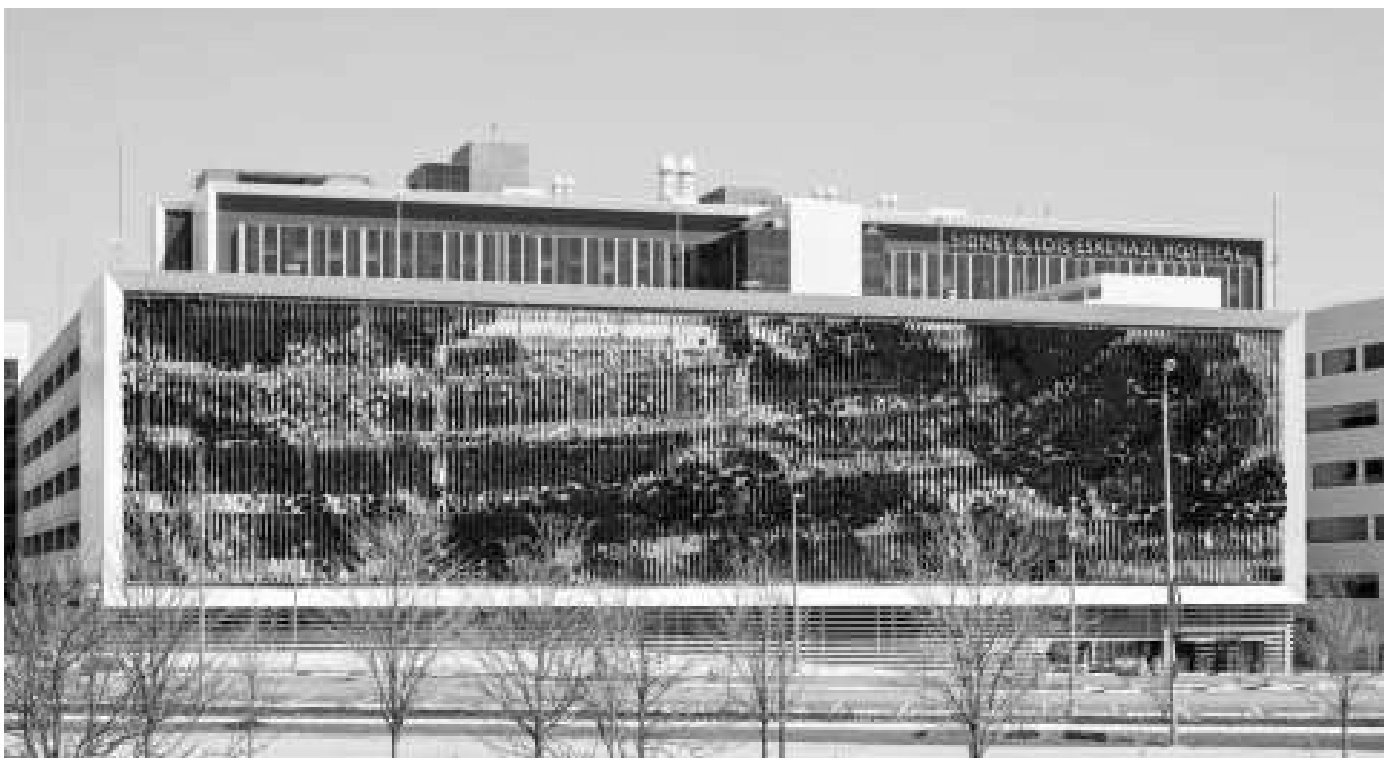

Figure 12. Eskenazi Hospital Parking Structure Art Facade by Rob Ley, Indianapolis, USA (https://www.arch2o.com/eskenazi-hospital-parking-structure-rob-ley-studio/). 


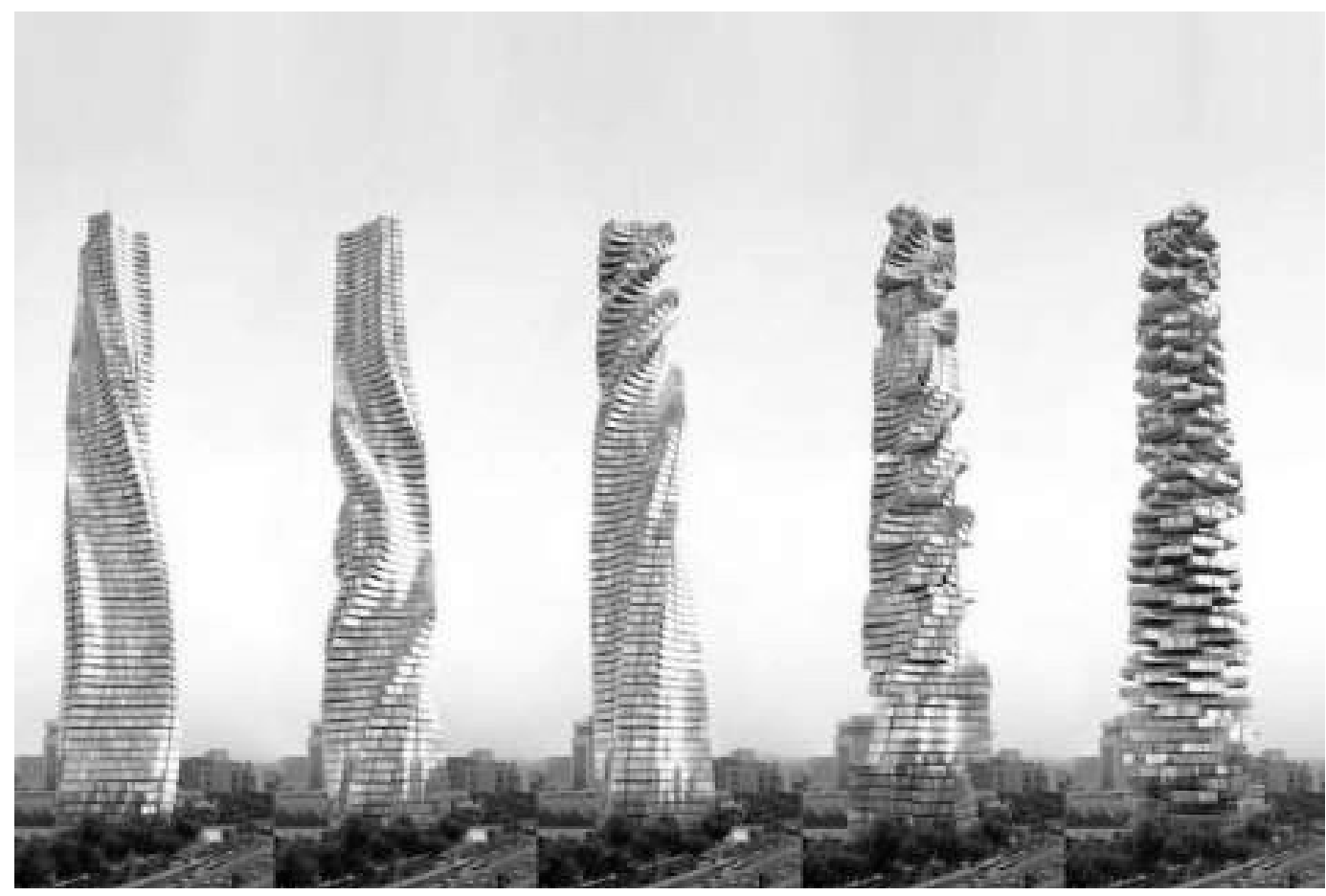

Figure 13. Rotated Tower by David Fisher, Dubai, UAE

(https://www.arch2o.com/dubais-rotating-tower-becoming-reality-2020/).

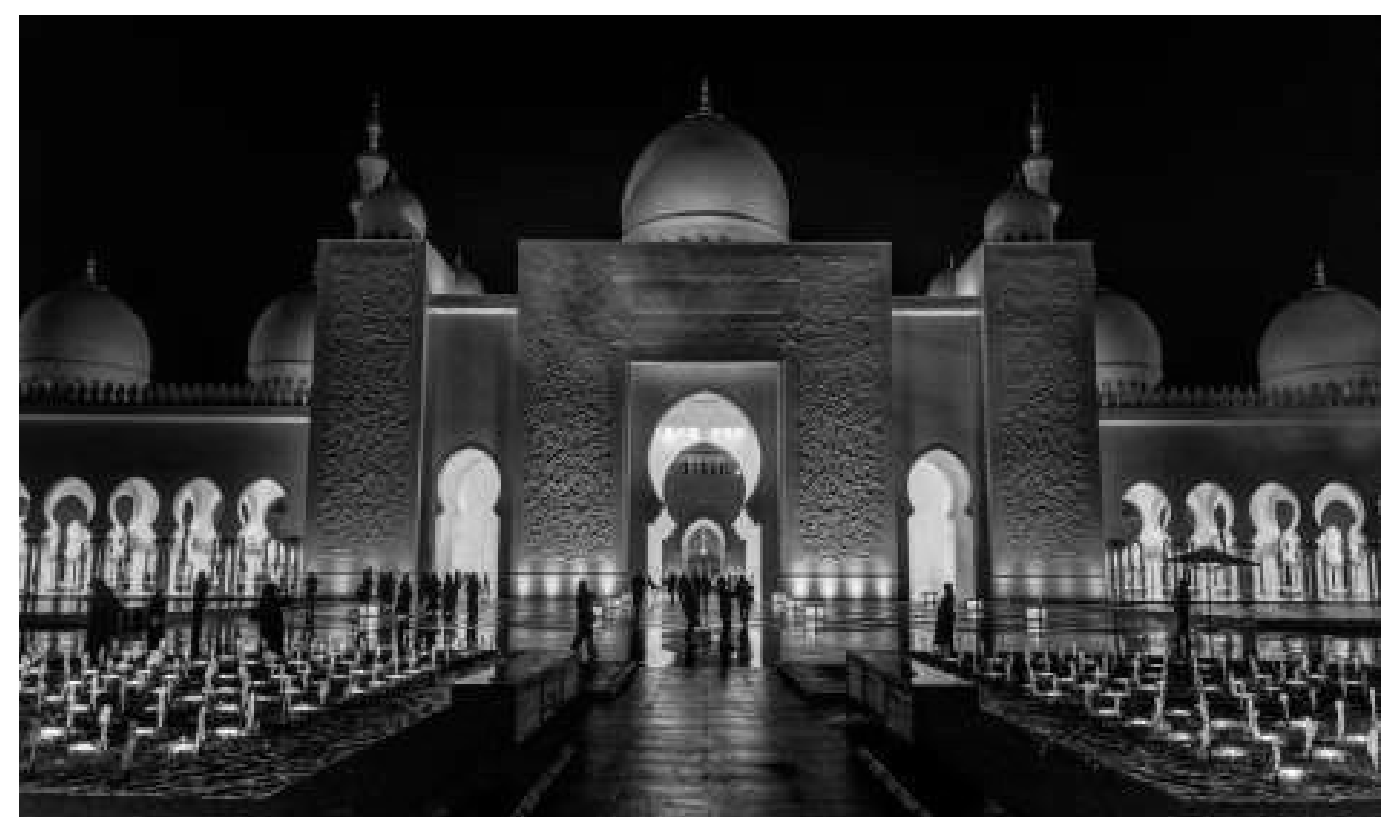

Figure 14. Sheikh Zayed Grand Mosque by Yousef Abdelky, Abu Dhabi, UAE (https://rove.me/to/uae/sheikh-zayed-grand-mosque-abu-dhabi). 


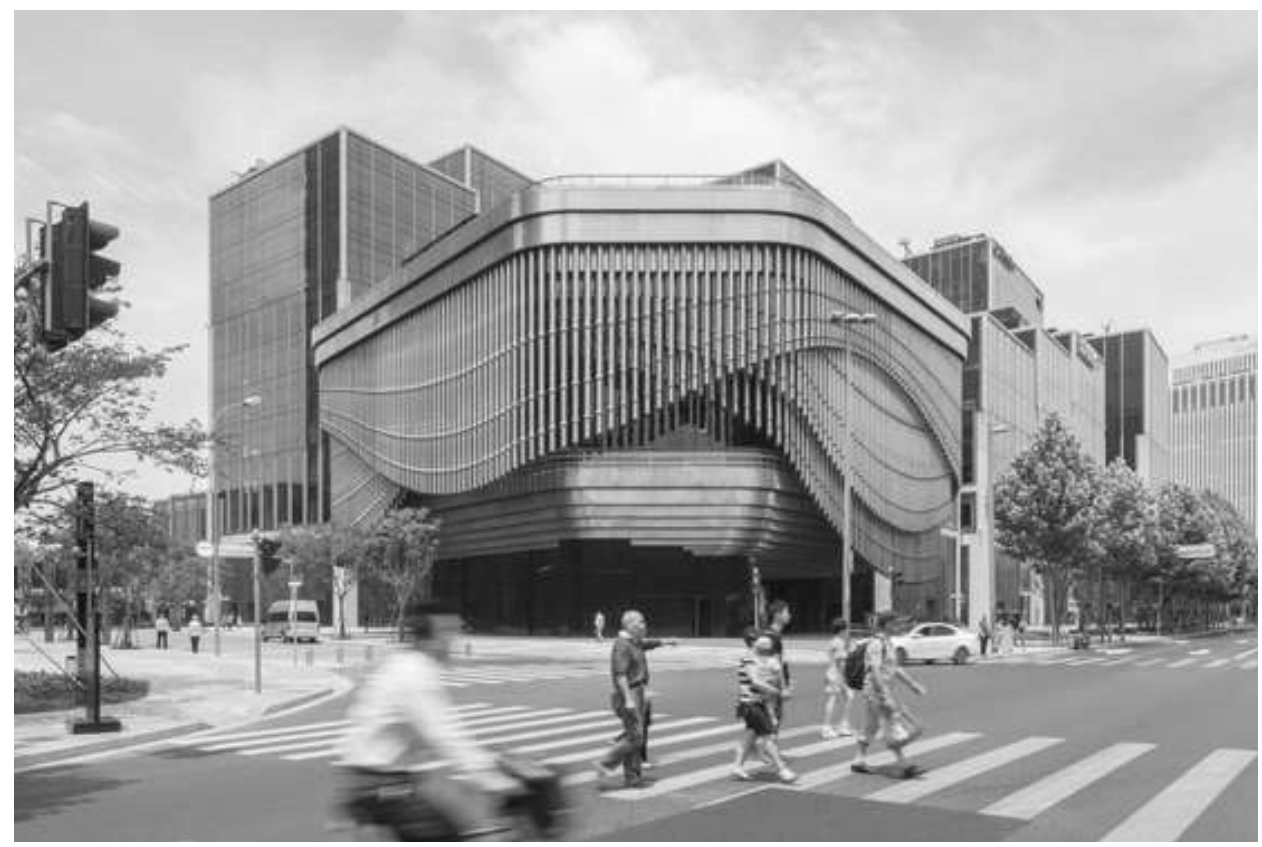

Figure 15. Shanghai Finance Center by Heatherwick Studio and Foster, Shanghai, China (https://www.architonic.com/en/project/foster-partners-the-bund-finance-center/5105770).
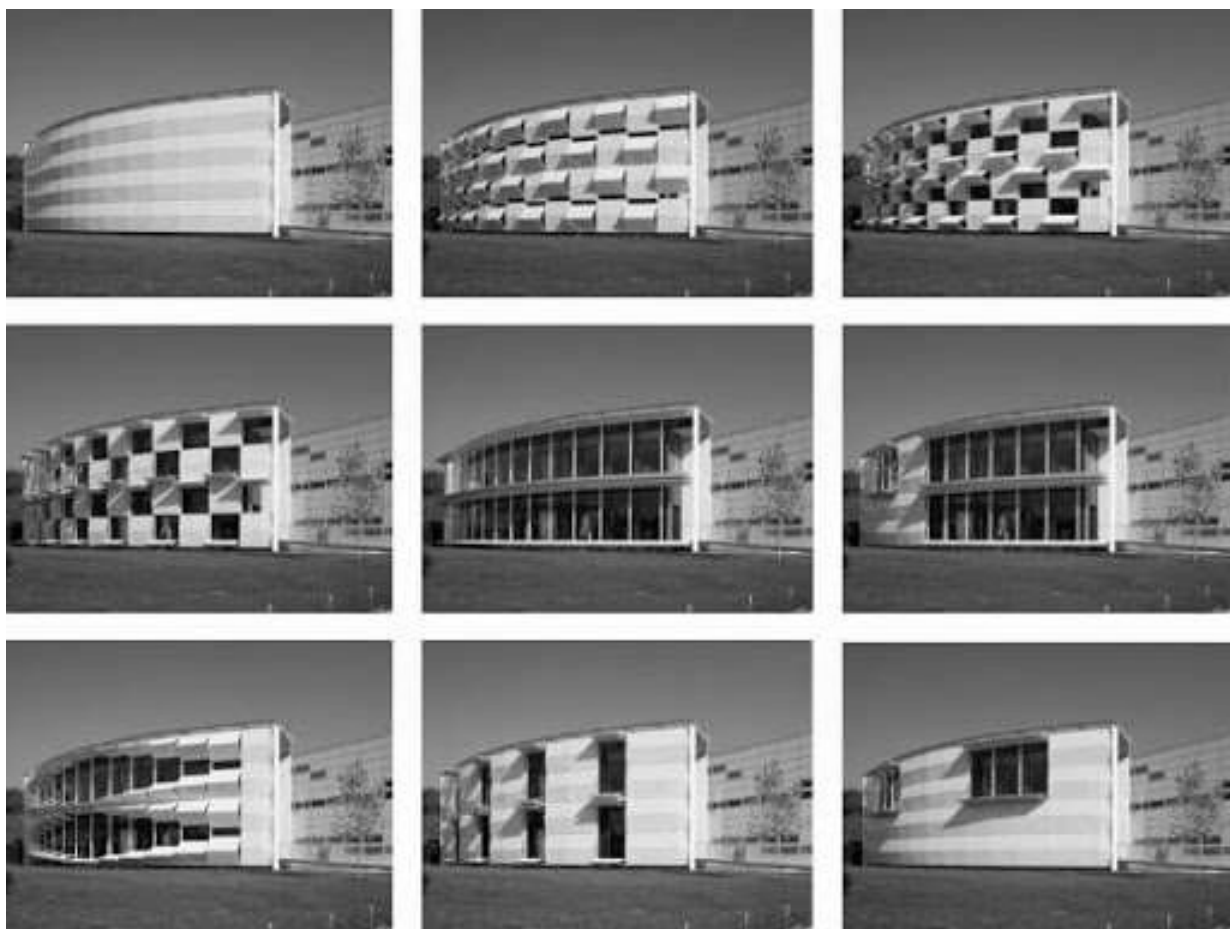

Figure 16. The Kiefer Technic Showroom by Ernst Giselbrecht, Steiermark, Austria (https://medium.com/@TheKoopa/kinetic-architecture-5ad7442f6b9d). 


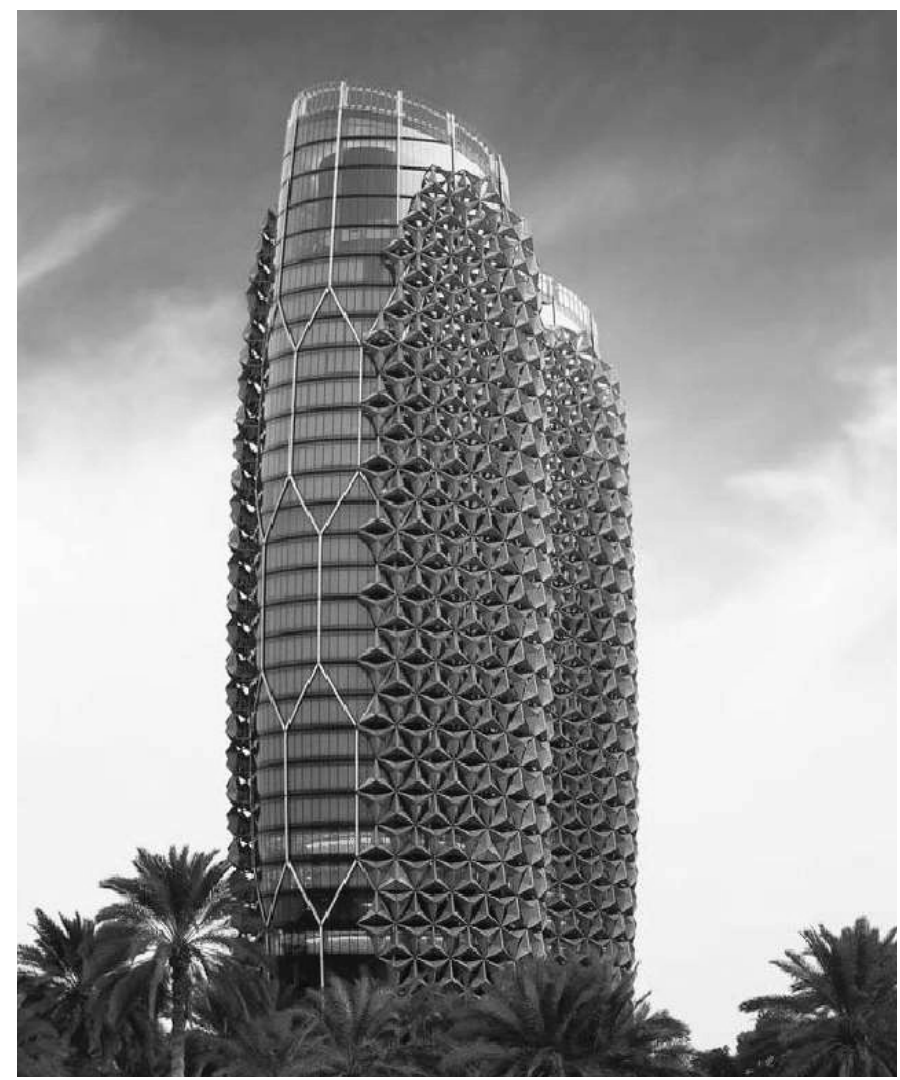

Figure 17. Al Bahr Towers by Aedas Architects, UAE

(https://www.researchgate.net/figure/The-Al-Bahr-Towers-is-a high-performance-design-inspired-by-its context_fig1_283683836).

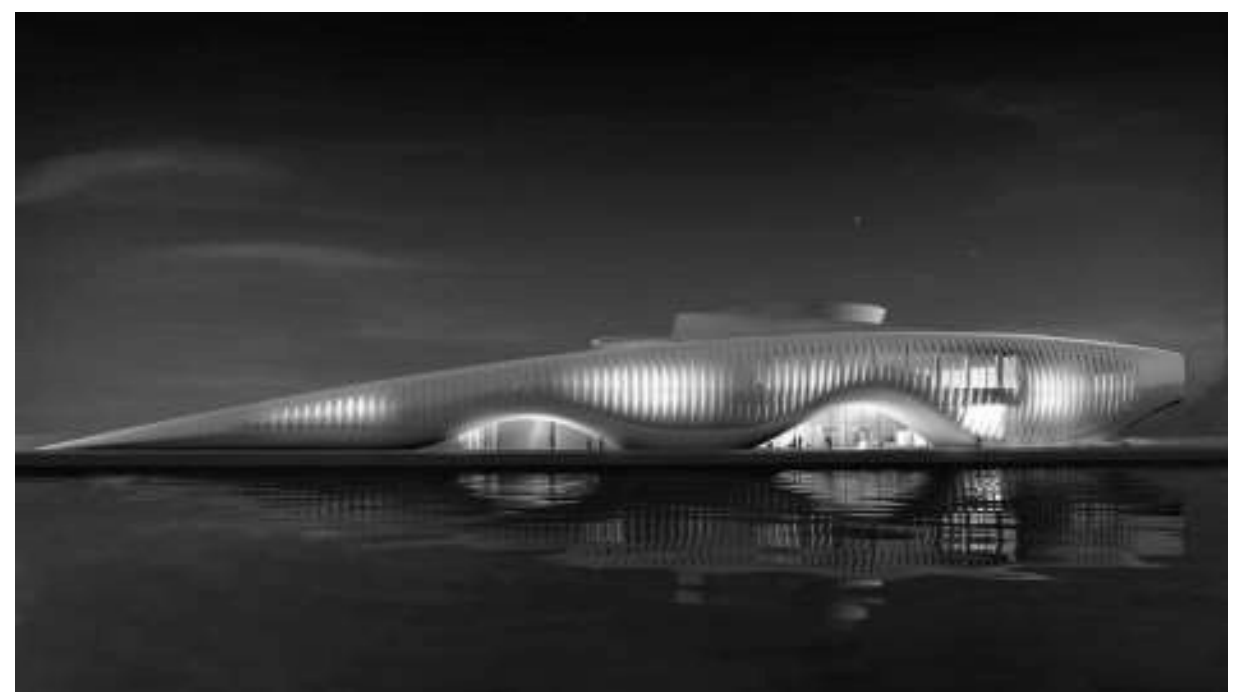

Figure 18. One Ocean Thematic Pavilion EXPO by Soma Lima, South Korea (https://images.adsttc.com/media/images/55e8/8cff/46fe/9f02/4f00/0007/large_jpg/soma_exy_night01.jpg?1441303779). 


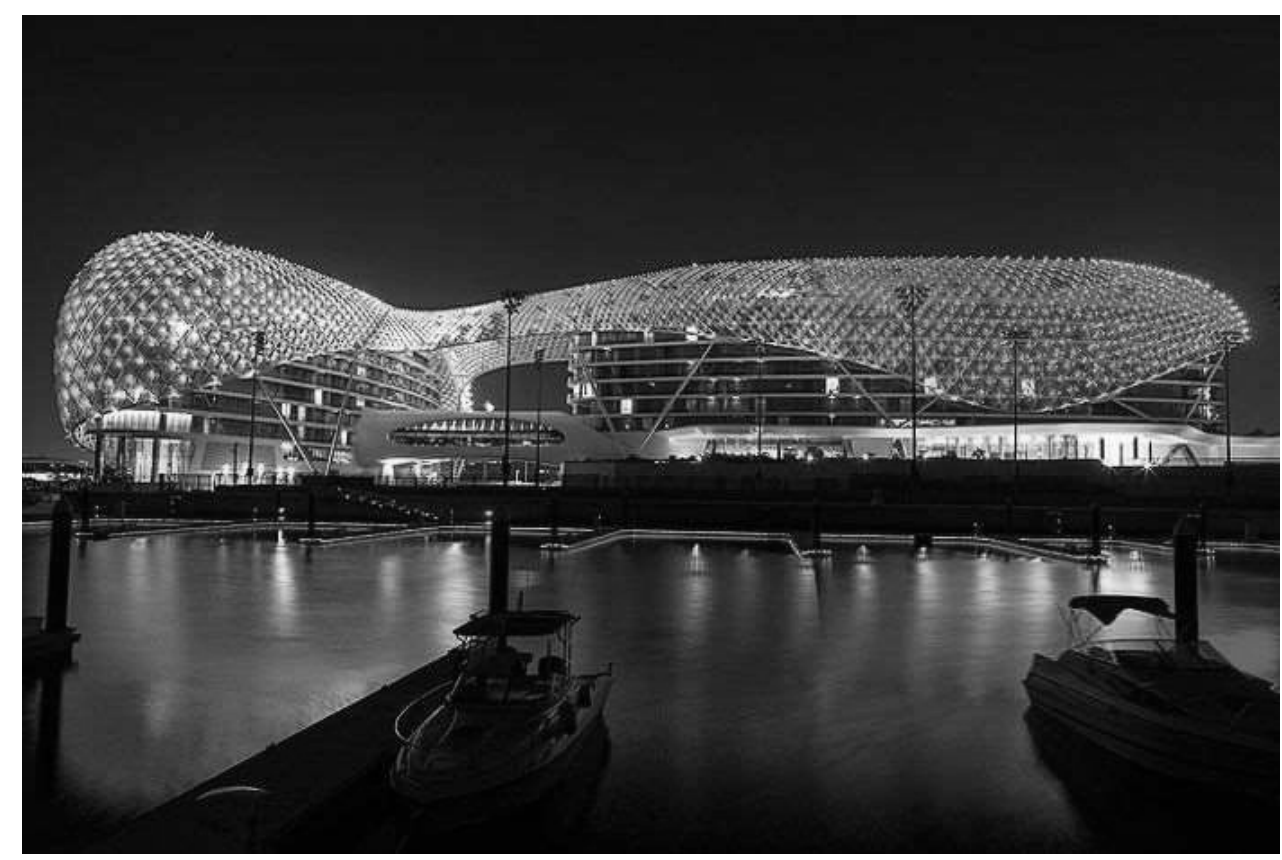

Figure 19. Yas Hotel by Asymptote, Abu Dhabi, UAE (https://www.pinterest.com/pin/56224695321312715).

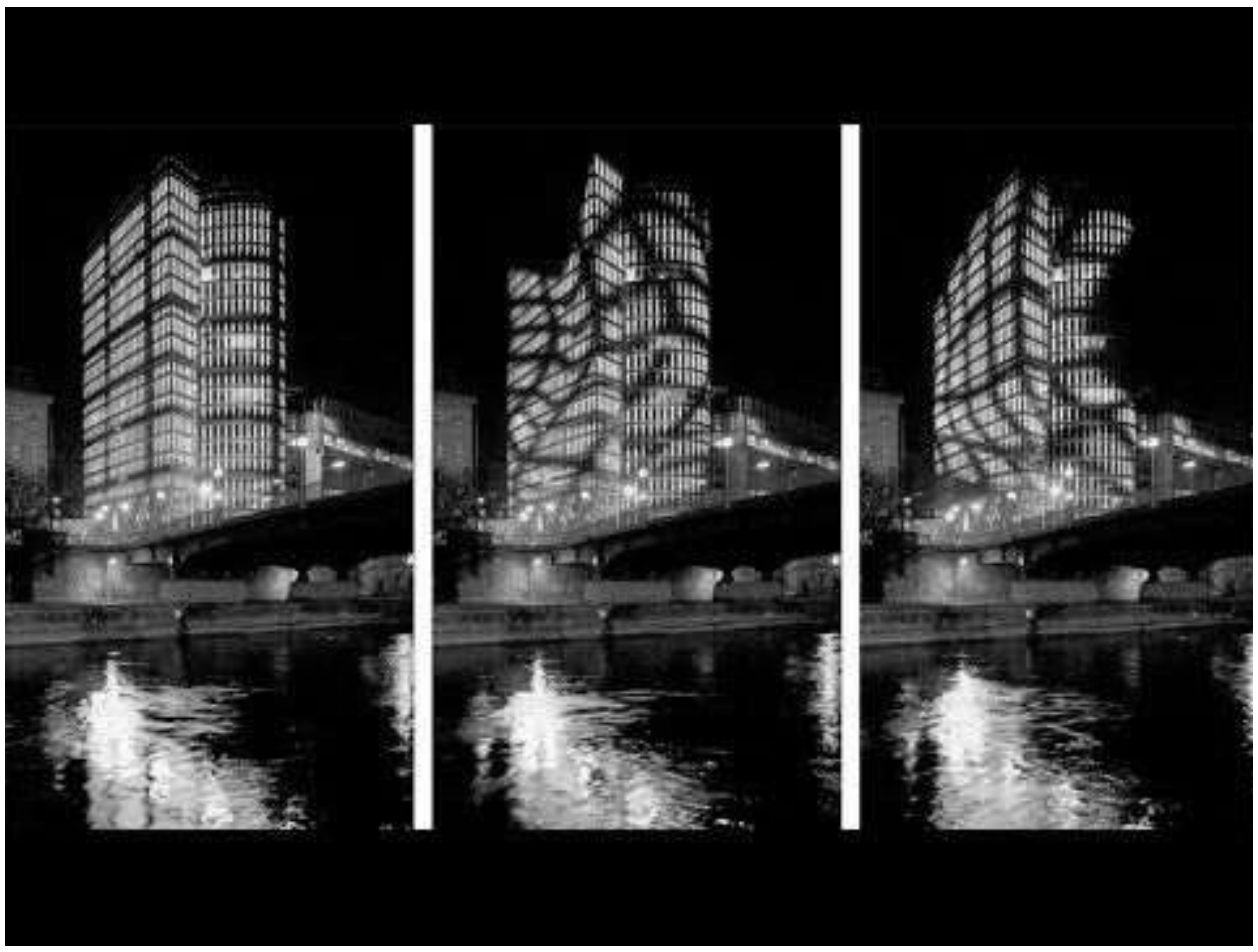

Figure 20. Twists and Turns by Mader Stublić Wiermannin Vienna, Austria (https://i.pinimg.com/originals/63/3a/1c/633a1c48a0249b46ffa5a3defb4f187a.jpg). 


\section{RESULTS AND DISCUSSIONS}

Table 1. The grade of changes in image of buildings façades (Change), (Researchers).

\begin{tabular}{|c|c|c|c|c|c|c|c|c|c|c|c|c|c|c|c|c|}
\hline \multirow{4}{*}{$\dot{0}$} & \multirow{3}{*}{ 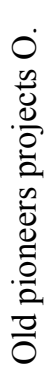 } & \multirow{3}{*}{$\begin{array}{l}z \\
0 \\
0 \\
\frac{0}{0} \\
0 \\
0 \\
0 \\
0 \\
0 \\
0 \\
0 \\
z \\
0 \\
z\end{array}$} & \multicolumn{10}{|c|}{ Image change in these sub categories } & \multirow{2}{*}{\multicolumn{2}{|c|}{ 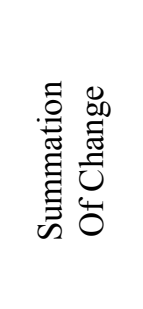 }} & \multirow{2}{*}{\multicolumn{2}{|c|}{ 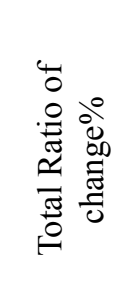 }} \\
\hline & & & \multicolumn{2}{|c|}{$\begin{array}{l}\frac{2}{8} \\
0 \\
\frac{\pi}{\pi} \\
\frac{0}{2} \\
\frac{1}{2}\end{array}$} & \multicolumn{2}{|c|}{ 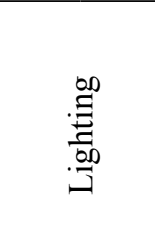 } & \multicolumn{2}{|c|}{$\frac{\overline{0}}{0}$} & \multicolumn{2}{|c|}{ 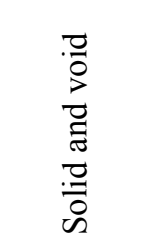 } & \multicolumn{2}{|c|}{ 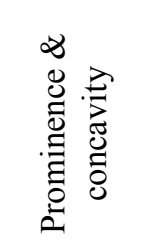 } & & & & \\
\hline & & & $0^{\circ}$ & $\dot{z}$ & $\dot{0}$ & $\dot{z}$ & $\dot{0}$ & $\dot{Z}$ & $\dot{0}$ & $\dot{z}$ & $\dot{0}$ & $\dot{Z}$ & 0 & $\dot{Z}$ & $\dot{0}$ & $\dot{Z}$ \\
\hline & $\stackrel{\infty \dot{D}}{\dot{I}}$ & 官 & $\frac{1}{0}$ & $\frac{r}{0}$ & $\frac{N}{0}$ & $\frac{n}{3}$ & $\frac{n}{3}$ & $\frac{1}{0}$ & $\frac{\sim}{-1}$ & $\frac{n}{0}$ & $\frac{\widetilde{\sigma}}{\hat{0}}$ & $\frac{n}{0}$ & $\cong$ & 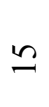 & \multicolumn{2}{|c|}{$\partial^{0}$} \\
\hline 1 & - & $=$ & 0 & 2 & 0 & 0 & 0 & 1 & 0 & 2 & 0 & 2 & 0 & 7 & 0 & 47 \\
\hline 2 & $\sim$ & 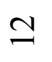 & 0 & 0 & 0 & 0 & 0 & 1 & 0 & 0 & 0 & 1 & 0 & 2 & 0 & 13 \\
\hline 3 & $m$ & 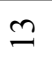 & 0 & 2 & 0 & 0 & 0 & 1 & 0 & 2 & 0 & 2 & 0 & 7 & 0 & 47 \\
\hline 4 & $\nabla$ & $\Xi$ & 0 & 0 & 0 & 2 & 0 & 2 & 0 & 0 & 0 & 0 & 0 & 4 & 0 & 27 \\
\hline 5 & in & $\stackrel{n}{n}$ & 0 & 1 & 0 & 0 & 0 & 1 & 0 & 2 & 0 & 1 & 0 & 5 & 0 & 33 \\
\hline 6 & 6 & $\underline{6}$ & 0 & 1 & 0 & 0 & 0 & 1 & 0 & 2 & 0 & 1 & 0 & 5 & 0 & 33 \\
\hline 7 & $r$ & 그 & 0 & 1 & 0 & 0 & 0 & 1 & 0 & 2 & 0 & 1 & 0 & 5 & 0 & 33 \\
\hline 8 & $\infty$ & $\infty$ & 0 & 1 & 0 & 0 & 0 & 1 & 0 & 1 & 0 & 0 & 0 & 3 & 0 & 20 \\
\hline 9 & $a$ & 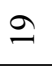 & 0 & 0 & 0 & 2 & 0 & 2 & 0 & 0 & 0 & 0 & 0 & 4 & 0 & 27 \\
\hline 10 & 으 & ㄱ & 0 & 0 & 0 & 2 & 0 & 2 & 0 & 0 & 0 & 0 & 0 & 4 & 0 & 27 \\
\hline$\%$ & & & 0 & 26 & 0 & 20 & 0 & 43 & 0 & 37 & 0 & 27 & 0 & 31 & 0 & 31 \\
\hline
\end{tabular}

\section{Content of Table 1}

The research represents the figures from 1-10 in the second column beside the figures 11-20 in the third column; after that, there are five subcategories of change in façade image according to physical body, lighting, color, solid and void, and prominence and concavity. For each category, there are three grades $(0,1$, and 2$)$ depending on the amount of change in image, which means that there are 15 different grades for each example.

According to Table 1, the research found the ratio of change in façade image as follows:

- In general, the change in façade image of buildings designed by new pioneers has a medium ratio, between 13 and 47 percent for each sample, $31 \%$ on average totally.

- In general, buildings designed by old pioneers have the lowest value, (0) for all samples, $0 \%$ on average totally.

- Figures 11 and 13 have the highest value among new pioneers' samples, 47\%.

- Figure 12 has the lowest value among new pioneers' samples, $13 \%$.

- Total change in façade image of buildings designed by new pioneers has $26 \%$ due to change in physical body, 
$20 \%$ due to change in lighting, $43 \%$ due to change in color, $37 \%$ due to change in solid and void, and $27 \%$ due to change in prominence and concavity.

- All changes in façade image of buildings designed by old pioneers were $0 \%$.

- Generally, whenever the architectural facade image changes, it will lose some of its concept, which is image constancy.

\section{CONCLUSION}

From the discussions, the following are noticed:

- The medium range of change in façade image of buildings designed by new pioneers confirms the hypothesis of the research, which is the lack of image constancy in contract to the result that there are no changes in façade image of buildings designed by old pioneers, which is a strong image constancy.

- The examples, which are belonging to the category of change in the physical body, are the most extreme changeable façade images, so they have the most changeable facades.

- The examples, which are belonging to the category of change in the prominence and concavity, are the least changeable façade image.

- Changeable façade images lost a part of its concept due to losing the property of having image constancy.

- Discovering the fact that architectural facade's concept was changed leads to observing emergence of new concept for it.

- Changes in the concept of architectural facade lead to a change in architectural appearance, and other concepts of facade deserve to be studied in the future; maybe there are also new characters that received a great role in representing the architectural form.

\section{REFERENCES}

Arnheim, Rudolf. 1977. Solids and Hollows, the dynamics of architectural form. London, University of California Press Ltd.

Aydogan, Esra. 2009. From advertising architecture to media facade communication through digital display skin.

Baker, John Milnes, A.I.A. 1994. American House Styles: A Concise Guide, Norton.

Bawa, Sanmukh. 2019. Glazing into the Future, How Media Façades Will Change Our Cityscapes. (https://wfmmedia.com/ glazing-into-the-future-how-media-facades-will-change-our cityscapes/)

Hill, Dan. 2008. Façades: expressive, responsive, and interactive. (https://www.cityofsound.com/blog/2008/01/faades-expressi.html)

Kroner, W.M. 1997. An intelligent and responsive architecture. Automation in Construction. (6), 381393.

Liu, Peng, 2001. Living Façades, Ball State University, Muncie, IN 47306- 0305, USA.

Moloney, J. 2009. A morphology of pattern for kinetic facades, T. Tidafi and T.Dorta (Eds.), Grammars of designs and grammars for designing, grammar based patterns for urban design. Montreal, 201213.

Nady, Riham. 2016. Dynamic Facades Environmental Control Systems for Sustainable Design, Renewable Energy and Sustainable Development (RESD) Volume 3 Issue 1, Special Issue, March 2017 - ISSN 2356-8569

Ruby, Ilka \& Andreas. 2007. Spatial Communication: A New Quality of Media Architecture in the Work of realities united.

Schieck, Ava Fatah gen. 2006. Towards an integrated architectural media space, First Monday, SpecialIssueno.4(February2006). (http://www.firstmonday.org/issues/special11_2/fatah/index.html) accessed October 31, 2007

Schumacher, Michael. With others 2010. Move, Architecture in motion, Dynamic components and elements. Berlin: Birkhauser.

Sharaidin, Kamil \& Salim, Flora. 2012. Design Considerations for Adopting Kinetic Facades 